\title{
Taking Horror as You Find It: From Found Manuscripts to Found Footage Aesthetics
}

\section{ABSTRACT}

An authenticator of the story and a well-tested enhancer of immersion, the trope of the found manuscript has been a persistent presence in Gothic writing since the birth of the genre. The narrative frame offered by purported textual artifacts has always aligned well with the genre's preoccupation with questions of literary integrity, veracity, authorial originality, ontological anxiety and agency. However, for some time now the application of the found manuscript convention to Gothic fiction has been reduced to a mere token of the genre, failing to gain impact or credibility. A revival of the convention appears to have taken place with the remediation and appropriation of the principally literary trope by the language of film, more specifically, the found footage horror subgenre. The article wishes to survey the common modes and purposes of the found manuscript device (by referring mostly to works of classical Gothic literature, such as The Castle of Otranto, Dracula and Frankenstein) to further utilize Dirk Delabastita's theories on intersemiotic translation and investigate the gains and losses coming with transfiguring the device into the visual form. Found footage horrors have remained both exceptionally popular with audiences and successful at prolonging the convention by inventing a number of strategies related to performing authenticity. The three films considered for analysis, The Blair Witch Project (1999), Paranormal Activity (2007) and REC (2007), exhibit clear literary provenance, yet they also enhance purporting credibility respectively by rendering visual rawness, appealing to voyeuristic tastes, and exploiting susceptibility to conspiratorial thinking.

Keywords: found manuscript, found footage horror, Gothic fiction, intersemiotic translation. 


\section{TAKING HORROR AS YOU FIND IT: FROM FOUND MANUSCRIPTS TO FOUND FOOTAGE AESTHETICS ${ }^{1}$}

In the editor's note to the sixth issue of Text Matters devoted to Gothic aesthetics, Agnieszka Soltysik Monnet stresses the shifting cartographies of Gothic studies, pointing to scholars' burgeoning interest in the material foundations of the Gothic, be it the physicality of the body or economic, political and cultural conditionings of the day that Gothic aesthetics have been persistently subverting (7). The material turn, one might infer, seems to have impaired critical interest in structural features of Gothic narratives, the found manuscript likely topping the list of the most commonplace and unstimulating tropes that define the genre. Part and parcel of Gothic fiction ever since its very beginnings in the eighteenth century, the convention of the found manuscript has been recognized by both scholars and readers as the epitome of generic tokenization, an instance of Jamesonian pastiche which offers "a knowing nod to literary tradition that is in itself unilluminating" (Baker 56), thus fated to deserve little consideration. Concurrently, however, a number of scholars in the field assert that the device is still relevant to the modern-day preoccupations of the Gothic genre. In his study of found manuscripts and frame narratives as purveyors of Gothic subjects' anxiety over their narrative expression and repression, Daniel Southward renders the trope as "endemic ..., yet so often critically neglected" (45). Timothy C. Baker suggests that it "still merits investigation" (57) to further prove its significance in highlighting the intricacies of text, language and the past as evident in Scottish Gothic fiction (55). The focus of the following study is to indicate yet another fruitful locus from which to consider the significance of concocted, framegenerating artifacts in constructing Gothic fictions-a distinctive shift in their modality, from the literary to the visual, which accordingly invites one to expose the alterations taking place in transit. The abundance of and continuing demand for found footage horror movies reveals that what originated as a literary convention appears to have lost its potency to regain it in the realm of the visual, where new ways of fabricating authenticity have emerged to better immerse and resonate with modern-day audiences. Borrowing from Horace Walpole's The Castle of Otranto (1764), Mary Shelley's Frankenstein (1818) and Bram Stoker's Dracula (1897), the analysis begins with an overview of the roles that the convention of the found manuscript plays to enable Gothic writers to simultaneously

\footnotetext{
Acknowledgement: the project is financed from the grant received from the Polish Ministry of Science and Higher Education under the Regional Initiative of Excellence programme for the years 2019-22, project number 009/RID/2018/19, the amount of funding 8791 222,00 PLN.
} 
counterfeit authenticity and distance their authorship. Given that the two latter works do not manifest themselves as found manuscripts in the strict sense, I wish to understand the found manuscript as any embedded textual artifact which poses as real and adds to the narrative progress of the novel. The subsequent part of the study surveys the transmutation of the convention into the domain of found footage aesthetics through the prism of intersemiotic translation and Dirk Delabastita's theory of translational operations which characterize the process of transcoding the source text into the target text. In harmony with the now-classic status of the three novels analyzed, the target corpus comprises three classic found footage horror films, The Blair Witch Project (dir. E. Sánchez and D. Myrick, 1999), Paranormal Activity (dir. O. Peli, 2007) and [REC] (dir. J. Balagueró and P. Plaza, 2007), allowing one to better discern the correspondences between the works which proved to be revolutionary in their respective fields, owing largely to the convention of the found artifact.

\section{LOOKING THROUGH FOUND MANUSCRIPTS}

In her seminal work on the use of discovered manuscripts in the Gothic genre, Fiona Robertson observes that "the device ... offered Gothic writers one way of authenticating and simultaneously distancing material" (94). Arguably still the central rationale behind deploying the trope in Gothic fiction, the above-mentioned tactics converge as early as in the preface to the first edition of genre-defining The Castle of Otranto (1764), in which Horace Walpole, a self-declared translator "from the purest Italian" (4), asserts that the manuscript of Otranto "was found in the library of an ancient Catholic family in the north of England" and must have been written in the time of the Crusades (4). The remoteness of the purported time and place of its origin (Naples) on the one hand allows Walpole to feign historicity of the artifact and, on the other, is conducive to legitimizing the uncanniness which is about to follow- "miracles, visions, necromancy, dreams, and other preternatural events" (5). As evidenced by another frame narrative analyzed, Mary Shelley's Frankenstein, what also lends to the veracity of ostensible artifacts is their dependence on scientific references and lexis. The introductory chapters of the novel forming Victor Frankenstein's account are largely devoted to reminiscences of his educational pursuits. Frankenstein saturates his story with mentions of Heinrich Cornelius Agrippa, Albertus Magnus and Paracelsus, as well as with numerous hints at theories on electricity and galvanism ("Chapter 2"). This part of Shelley's work leaves the reader with a palpable imprint of 
a scientific argument, which synthesizes data and offers a purported line of investigation to culminate in the demonstration of findings. Verisimilitudes of scientific discourse also characterize Dracula, a work heavily inspired by Shelley's masterpiece, adding to its allure of authenticity. Providing the reader with observations on Renfield, an insect-eating patient confined to an asylum, Dr. Seward's diary entries exercise clinical typology and allude to experts in the field of medical theory:

I shall have to invent a new classification for him, and call him a zoophagous (life-eating) maniac.... Why not advance science in its most difficult and vital aspect— the knowledge of the brain? Had I even the secret of one such mind ... I might advance my own branch of science to a pitch compared with which Burdon-Sanderson's physiology or Ferrier's brain knowledge would be as nothing. (Stoker 90)

Hailed by Steward as "one of the most advanced scientists of his day" (137), Professor Van Helsing is another character whose sequential and methodical approach to curing Lucy Westenra, as well as to battling vampires authenticates and solidifies the realistic strata of the novel. Interestingly enough, as noted by Carol A. Senf, Van Helsing "takes advantage of contemporary science while at the same time maintaining heavy skepticism about its efficacy" (23), thus leaving space for what is unfathomable to a rational mind and relevant exclusively to folklore.

Shifting focus to another mode of purporting veracity, although not found manuscripts on the overarching level of narrative, both Frankenstein and Dracula exercise the discussed device inasmuch as they noticeably reify the embedded narratives and the very act of finding (out). While deploying multiple textual forms, Shelley and Stoker likewise fashion their subnarratives as real documents, which are to astound the characters themselves and subsequently to be legitimized by them. In Dracula the successful polyphony of literary artifacts (among many, letters, journals, logs, newspaper snippets and phonograph transcripts) owes largely to the fact that the characters take every effort to appreciate and authenticate each other's accounts. A prime example comes with one of Van Helsing's letters to Mina Harker in which he becomes touched by and awakened to the realities of Jonathan's captivity:

I have read your husband's so wonderful diary! You may sleep without doubt. Strange and terrible as it is, it is true! I will pledge my life on it.... His brain and his heart are all right; this I swear before I have even seen him; so be at rest. ... I am blessed that today I come to see you, for I have learn all at once so much that again I am dazzle—dazzle more than ever, and I must think. (Stoker 224) 
Mina's fears of Jonathan's derangement (as well as Jonathan's own dread of the fallibility of his senses) are mollified as her husband's account of confinement has been validated by another reader of the diary. Similar instances may be found in Frankenstein; in one of the final letters to his sister Robert Walton goes to great lengths to assure Margaret that Victor's "tale is connected and told with an appearance of the simplest truth," simultaneously endorsing other documents presented to him by Victor, that is, "letters of Felix and Safie" ("Walton, in continuation"). Thus, one's act of stumbling upon a textual artifact and validating it contributes to the overall performance of veracity both in Stoker's and Shelley's narratives. Such a use of the found manuscript device artfully protrudes into the relationship between the reader and the work which poses as real; readers of Frankenstein and Dracula are invited to emulate the model readers embedded in the texts and yield to the para-authentic substance of the novels.

Concomitant with attracting the reader into placing trust in recovered textual artifacts is the process of abandoning authorial responsibility for explicating the ways in which they interrelate. Thus, apart from being set in remote spaces to distance the author from his or her work (Otranto, Swiss and Arctic settings, and Transylvania in The Castle of Otranto, Frankenstein and Dracula respectively), the narratives which employ the convention of the found manuscript embrace narrative fragmentation, a mode which relocates the narrative authority from the author to the reader. Doing so, fragmented texts undermine the notions of authorship and ownership or, as Ruth Bienstock Anolik has it, literalize the strategy of dispossession, both on the level of the structure and materiality of manuscripts (130). Of the works referred to it is perhaps Frankenstein which exhibits the most potent manifestation of authorial dispossession, that is, the Creature's coming upon Victor Frankenstein's diary spanning four months preceding his creation. In a bitter tirade targeted at his creator the monster recites various accusations, among them appropriating his representation and agency: " $[\mathrm{T}]$ he minutest description of my odious and loathsome person is given, in language which painted your own horrors and rendered mine indelible. I sickened as I read" (“Chapter 15"). Confronted with the Creature's perspective, Victor's narrative discloses its own bias and loosens some of its control as an embedding structure. Victor admits that he "ought to render him [the Creature] happy before [he] complained of his wickedness" and he "consent $[\mathrm{s}]$ to listen" ("Chapter 10"). The dominant interpretation of the events is therefore "both resolved and challenged by another text" (Baker 65). As continued by Baker on the narrative framework in Frankenstein, "the tension of each narrative strand builds until it is replaced by another, and it is left to the reader to make 
sense of the various tales together" (65). Such dynamics of conflicting narratives do not leave the reader unaffected. If every "Gothic Subject, the framer or finder of their respective tale, presses the tale to serve their own agenda" (Southward 53), then the reader is ultimately deprived of any claim to objective reality. As specified by Anolik, fragmentation "clearly works to disrupt the reader's hermeneutic possession of the text as meaning falls between the gaps of the fragments" (130). The epistemic impasse triggered by fragmented manuscripts further problematizes gaining access to the past. In Baker's eyes, “[m] etafictional elements, including found manuscripts and clear forgeries, arguably highlight the extent to which any text, or work of language, fails to represent the past objectively or completely" (Baker 55). In Dracula such anxieties are typified by Jonathan Harker's torments over the reliability of his own journal entries as when he admits: "I was in doubt, ... . everything took a hue of unreality, and I did not know what to trust, even the evidence of my own senses" (Stoker 226). To dissolve both the objective sense of the past and himself from the text even further, Stoker notoriously makes his characters convert various records from one medium to another-journal entries are recorded onto phonograph, phonographic recordings are transcribed into text, the log of the "Demeter" is translated from Russian into English to be further copied by Jonathan. At the same time, journalistic forays in Stoker's novel make a continuous and daring attempt to save the past from obscurity and obliteration. Lucy's determination to render the events of Dracula's assault attests to the importance of recording one's story: "I feel I am dying of weakness, and have barely strength to write, but it must be done if I die in the doing" (172). In a similar vein, as she fears Jonathan's "lapsing into forgetfulness" (208), Mina exclaims: "[s] ome day he may ask me about it. Down it all goes" (206). Since what is either found or remembered may be easily lost, the characters in Dracula put every effort into preserving their records, be it Lucy "hiding ... paper in [her] breast" (175) or Mina's copying out Dr. Seward's phonographic recordings (264-65).

\section{REWRITING ARTIFACTS}

With the advent of digitalization and digitization processes, the proliferation of digital tools, and the dissemination of distribution channels at the break of $20^{\text {th }}$ and $21^{\text {st }}$ century, the Gothic genre was never to remain the same. Given the shift in media production and consumption, from user-passive and unidirectional to user-empowering and interactive, a globalized culture of participation could emerge and elevate storytelling to an entirely new level. Borrowing from Henry Jenkins's theories on participatory culture, 
Anthony Mandal asserts that "creative practice is increasingly being generated by prosumers [producer-consumers] who remix, remediate, and 'mash up' texts" (91), thus “[g] iving existing artworks and commercial products a new spin" (91). The inventiveness of the found footage horror film as a modern-day remediation of the found manuscript convention is no exception; it was clearly energized by digital innovation as clarified by Daniel Myrick, the co-director of The Blair Witch Project: "In the late 90s, with digital coming into its own, it was only a matter of time before someone made this kind of first-person movie" (Hoad). The question which remains to be answered is that of equivalence between the modalities of the literary and film variant of the device, a matter which invites examination through the prism of translation studies. Resorting to Jakobson's classic triadic division of translation, on the most general level the remodeling of the found manuscript trope into the found footage aesthetics appears to belong to the realm of intersemiotic translation, also known as transmutation, thus "an interpretation of verbal signs by means of signs of nonverbal sign systems" (233). ${ }^{2}$ Extending the definition, Nicola Dusi asserts that

[i]ntersemiotic translation can provisionally be said to take place when there is a re-presentation, in one or more semiotic systems . ..., of a form of the content intersubjectively recognized as being linked, at one or more levels of pertinence, to the form of the content of a source text. (184)

Despite its syncretic form, a film, as continued by Dusi, "should always be considered an aesthetic text” (185). The further investigation in registering gains and losses of transfiguring the discussed convention will be grounded in Dirk Delabastita's general typology of translational relationships between items of the source text which are being recoded into the target text. These are divided into five types: substitution, repetition, deletion, addition and transmutation. With the act of substitution "the relevant source text item is replaced by a target code item ... [with] a more or less equivalent relational value" (33-34) and, as aptly observed by Delabastita, "in strict recoding all relationships ... fall under this category" (34). Repetition occurs when an item is "merely repeated or transferred directly from the source text into the target text" (34). As regards deletion, "a particular source target item is not rendered in the target text at all, not even by

2 As rightly emphasized by Dirk Delabastita, when approaching the multimodality of film one must not forget that "the visual channel sometimes conveys verbal signs (e.g. credits, letters, shop signs) and that the acoustic channel transmits some non-verbal signs (music, background noise, etc.)" (qtd. in Munday 183). 
a low equivalence analogue" (35). In the case of addition, the target text "contain $[\mathrm{s}]$... signs that have no apparent antecedent in the source text" (36). Lastly, permutation holds that the position of the item within the target text "does not reflect the relative position of its source text" (36). Delabastita argues that the above-mentioned transformations operate along the lines of three main semiotic codes: a linguistic code, a textual code and a cultural code. A linguistic code indicates "minimal meaningful signs" (6) and the ways they combine in both the source and target text, amounting to the text grammar. In turn, a textual code revolves around the ways "a peculiar type of textual organization ... [is] impose[d] upon the linguistic material" (11); it is thus analogous to generic and narrative strategies of a given text. Finally, contextual aspects which always leave a stamp on the meaning of the source and target text belong to the concept of cultural code (14). The broad scope of Delabastita's framework helps to reveal the initial possibilities of intersemiotic reading of the conventions discussed, leaving space for further explorations of intersemiotic complexities. Given the multi-channel nature of film communication as opposed to single-channeled literature, as well as the heterogeneity of corpora comprising the source and target text of the analysis, my study will be predominantly limited to exploring parallels on the level of textual code, an anchor for generic codes and conventions, to which the tropes of found manuscript and found footage undoubtedly belong. A smaller number of observations on the linguistic code follows shortly after.

To begin with, what clearly articulates the literary provenance of found footage aesthetics is the plentitude of textual items which can be perceived in terms of Delabastita's category of repetition. Consistently with the source text, the films discussed distance the agency of the author while purporting to be authentic footage. Instead of showing the opening credits, both Paranormal Activity and The Blair Witch Project (henceforth $P A$ and $B W P$ ) attempt to trick the viewer into believing that the discovered video material has been in control of an alleged editor. With regard to the former film, such a role is assumed by Paramount Pictures, with help received from the "families of Micah Sloat \& Katie Featherston and the San Diego Police Department" $(P A)$; not long before the closing credits does the audience learn that the footage and Micah's body were found on 11 October 2006 and that "Katie's whereabouts remain unknown" $(P A)$. The latter film implies the presence of an editor as it informs the spectators about the disappearance of three student filmmakers "in the woods near Burkittsville, Maryland while shooting a documentary" (BWP) in October 1994; as the audience subsequently learns, "[a] year later their footage was found" $(B W P)$. As for $[R E C]$, the lack of opening credits rushes the viewer directly into the realm of two TV reporters following firefighters on their 
job, as much as it is possible to assume that the material has not been abridged at all. Limiting the focus to those literary works which utilize the found-manuscript device as a general frame for the entire narrative (Walpole's novel), the condensed settings of the three films appear to be also transcoded directly from the source text. The immediacy of setting the story in the Otranto castle finds its correlative in the close confines of the haunted house $(P A)$, the apartment building ([REC]) and the woods $(B W P)$, adding to the dramatic effect by emphasizing the sense of entrapment.

Another source text item which is repeated in the target text is the act of reifying and authenticating textual artifacts (bearing in mind Dusi's suggestion to perceive film as a textual form) by the characters themselves. The couple from $P A$ and the reporting duo from [REC] are much alike in their preoccupation with the recorded material, replaying, immersing themselves in and commenting on the registered footage. Such absorption is best typified by Micah, who appears to spend long hours over his personal computer and a hi-tech voice recorder to fathom the nature of the demonic presence which haunts his house. In a similar vein, Ángela, the reporter from $[R E C]$, instructs her cameraman to rewind and replay the shooting of one of the infected residents of the building, as if what she saw with her own eyes was inferior to what was filmed. The protagonists of found footage horrors highlight the importance of recording just as their literary counterparts do; Mina and Jonathan Harker's musings on the significance of keeping a journal correspond to fixation on the object of the camera as demonstrated by Micah, Ángela and Heather, the protagonist of $B W P$. The superior status of both the camera and the act of recording is implicitly conveyed in numerous scenes showing the very act. Bathroom mirror reflections in $P A$, as well as $B W P$ characters who film themselves filming augment authenticity and do not let the spectator forget about the power of the medium. Moreover, correspondingly to the source text, found footage horrors maximize the potential of recording as a means of preserving the veracities of one's traumas and altered states, which would otherwise be lost. In BWP Josh's and Mike's wishes to be kept out of shot are at odds with Heather's tenacity of belief in "get[ting] what [she] can" since "it's all $[$ she] ... has left" $(B W P)$. Similarly for Ángela, the footage of incidents in the apartment house is "the only proof [she and Pablo] have" ([REC]).

The final source text items repeated in the target text are the generic hybridity of the studied works and the tactics of implanting scientific references with the aim of reinforcing authenticity. Both $B W P$ and [REC] are simultaneously behind-the-scenes footage and the actual documentary which is being tried to be completed. Additionally, the latter film and $P A$ present themselves as hybrid forms by intercalating subtexts 
such as autopsy footage, newspaper clippings and tape recordings. The aforementioned scientific underpinning manifests in the characters of Dr. Fredrichs, a psychic called upon by Micah and Katie to investigate the demonic force that persecutes them $(P A)$ and a health inspector arriving at the scene of the quarantine ([REC]).

Although not as prevalent as repetition, other operations delineated by Delabastita are not absent from this intersemiotic transfer. For instance, the working of deletion is evident by the untransferred epistemic deadlock that the narrative fragmentation leads to in the source text novels. Each of the film narratives comprising the target text, albeit fragmented, does not seem to challenge the spectator with glaringly divergent visions of reality. As much as each of $B W P$ 's protagonists is a point-of-view narrator in their own respect, altogether they form a coherent narrative body with the dynamics harmonized by a common cause-survival. I would further argue that the films analyzed supersede the tactics of feigning historicity with the tactics of feigning immediacy, thus exhibiting textual substitution and attuning to the digital-era sensibilities concerning communication and information processing. Finally, what might be addressed in terms of permutation is the action of externalizing the main embedding frame from the body of text to the extratextual reality. Now considered a progenitor of innovative horror movie marketing, the marketing strategy of $B W P$ involved rendering the disappearance of students as factual (launching a website, distributing leaflets and "missing" posters). As argued by Marc Graser and Dade Hayes, this "was not an added-on marketing tool, but was designed as part of film experience" (qtd. in Telotte 36). If "Walpole's text was a forgery before it became a type" (Russett 13), so was BWP with its expanded frame for the story.

\section{ADDING UP TO AUTHENTICITY}

In Scars of the Spirit Geoffrey Hartman observes that

technology has created a new vein of gothic darkness. ... Augmented techniques of fictional deception, of entangling us in illusions, produce a strange mental indulgence. . . . Yet the psychology of art continues to reflect a spiritual pursuit: for "the One," the just, chosen, authentic work or individual on which everything depends. (qtd. in Baker 68)

Found footage horror films would not have been successful in channeling pursuits of authenticity, just as they would not have resonated extremely well with contemporary audiences, but for "an added value" they hold. Apart from repeating, deleting, transmuting and substituting generic items 
stemming from the literary tradition, the genre has developed its own unique filmic allure tied to the new channels of reinforcing authenticity. These, as I claim, involve purporting audiovisual rawness, exploiting voyeurism and activating conspiratorial impulses. Following the line of my argument I will address them as instances of Delabastita's addition, yet this has to be done with a simultaneous turn to the non-textual code they operate in.

The aforementioned audiovisual rawness is best typified by the way $B W P$ operates on the level of linguistic code. Upon seeing a shaky title board, the viewer is prone to think that what will follow is amateur filmmaking which will not seek technical excellence. Doubts are gone when the protagonists set out their hopes and fears about their film project. Before the proper shooting begins, Heather declares: "I want to really avoid any cheese. I want to present it in as straightforward a way as possible" $(B W P)$. Handling a borrowed camera, Josh admits that "[he's] used it, like, once before" ( $B W P)$. Far from exaggeration, the audiovisual grammar of the film excels at professing the video footage as raw and credible. It abounds in shaky tracking shots, abrupt cutting, distorted vision, lack of noise-cancellation and poor framing (climaxing with the now iconic extreme close up of Heather's eyes). Connected to this is the role of dialogue - the protagonists curse, tell dirty jokes and mock the national anthem, attuning the viewer to the mood of extreme informality. Much is also channeled through the linguistic code of $P A$. Differently than in $B W P$, Peli's film reinvigorates authenticity by thematizing the cutting edge recording technologies and inviting the viewer to penetrate deep into the everyday lives of the protagonists. Micah's idea to film the daily routines of his household, as well as to set up a camera in the bedroom with a view to registering supernatural phenomena, harmonizes with the modern-day public spectacle of self-exposure (as exemplified by postings on Instagram, Facebook, YouTube, etc.) and the spectators' unrelenting voyeuristic demand for it. The panoptic camerawork, resembling the supervision of CCTV, seems to additionally coalesce with the viewer's eye to exercise surveillance over Micah and Katie.

Finally, the "critiques of traditional institutions" (Soltysik Monnet 8), as well as appreciation for "alternative epistemologies" (8), as typified by the Gothic, come to a full manifestation in [REC], adding visual force to its cultural subversiveness. Striking the conspiratorial note and viewing the institutions of systemic power (police, army and, presumably, city officials) in a negative light, the film implies that maintaining faith in the sources of institutional trust is no longer possible. Preventing the reporters from filming, as well as denying access to information to the residents of the apartment block attests to the failure of the system which denies one knowledge and participation. The need for alternative, thus 
authentic, channels of information and representation is well addressed and highlighted by the visual grammar of [REC]. Shaky tracking shots (often the effect of scuffles between the reporters and the police), plenty of zooming and the inquisitiveness of the camera (filming even when fallen to the ground) appear to operate in the fluid, unregulated realm, somewhere between the expectations and limitations of the system. What is at stake is the preservation of the material copy of the recording, an artifact to be found and embraced as an authentic and unregulated testimony.

To conclude, the aesthetics of the found footage horror film build heavily on the literary convention of the found manuscript as evidenced by repeating, substituting and transmuting features of its code. Concurrently, it departs from the literary source in search of its own diction, both generic and audiovisual. It also stands at the nexus of the past, present and future as it anticipates further digital evolution of the trope, already signaled by video game narratives such as Resident Evil 7 (Capcom, 2017) and Her Story (Sam Barlow, 2015). One might be similarly optimistic about the prospects reinvigorating the convention in literature. As argued by Catherine Spooner, "the labyrinthine intricacies of the World Wide Web create the potential for all kinds of felicitous discoveries, while sophisticated word-processing programmes permit ever-more elaborate arrangements of texts" (39), resulting in innovative fiction such as James Paterson's The Chef (2019), a text for Facebook Messenger, and leaving the trope fertile for further critical debates and inquiries.

\section{Works CiTED}

Anolik, Ruth Bienstock. Property and Power in English Gothic Literature. Jefferson, NC: McFarland, 2016. Print.

Baker, Timothy C. Contemporary Scottish Gothic: Mourning, Authenticity, and Tradition. Basingstoke: Palgrave Macmillan, 2014. Print.

Delabastita, Dirk. There's a Double Tongue: An Investigation into the Translation of Shakespeare's Wordplay. Amsterdam: Rodopi, 1993. Print.

Dusi, Nicola. "Intersemiotic Translation: Theories, Problems, Analysis." Semiotica 206 (2015): 181-205. Print. https://doi.org/10.1515/sem2015-0018

Hoad, Phil. "How We Made The Blair Witch Project." Theguardian.com. The Guardian 21 May 2018. Web. 2 Jun. 2019.

Jakobson, Roman. "On Linguistic Aspects of Translation." On Translation. Ed. Reuben Brower. New York: Oxford UP, 1966. 232-39. Print.

Mandal, Anthony. "Gothic 2.0: Remixing Revenants in the Transmedia Age." New Directions in 21 ${ }^{\text {st }}$ Century Gothic: The Gothic Compass. Ed. 
Lorna Piatti-Farnell and Donna-Lee Brien. London: Routledge, 2015. 84-100. Print.

Munday, Jeremy. Introducing Translation Studies: Theories and Applications. London: Routledge, 2016. Print. https://doi.org/10.4324/9781315691862 Paranormal Activity. Dir. Oren Peli. Perf. Katie Featherston, Micah Sloat. Solana Films, 2007. DVD.

[REC]. Dir. Jaume Balagueró and Paco Plaza. Perf. Ferran Terraza, Manuela Velasco. Castelao Producciones, 2007. DVD.

Robertson, Fiona. Legitimate Histories: Scott, Gothic, and the Authorities of Fiction. Oxford: Clarendon, 1994. Print. https://doi.org/10.1093/acp rof:oso/9780198112242.001.0001

Russett, Margaret. Fictions and Fakes: Forging Romantic Authenticity, 1760-1845. Cambridge: Cambridge UP, 2009. Print.

Senf, Carol A. Science and Social Science in Bram Stoker's Fiction. Westport, CT: Greenwood, 2002. Print.

Shelley, Mary. Frankenstein. Gutenberg.org. Project Gutenberg 2008. Online text.

Soltysik Monnet, Agnieszka. "Gothic Matters: Introduction.” Text Matters 6 (2016): 7-14. Print. https://doi.org/10.1515/texmat-2016-0001

Southward, Daniel. "Frame Narratives and the Gothic Subject." The Dark Arts Journal 1 (2015): 45-53. Print.

Spooner, Catherine. Contemporary Gotbic. London: Reaktion, 2007. Print. Stoker, Bram. Dracula. London: Penguin, 1994. Print.

Telotte, J. P. “The Blair Witch Project: Film and the Internet." Film Quarterly 54.3 (2001): 32-39. Print. https://doi.org/10.1525/fq.2001.54.3.32

The Blair Witch Project. Dir. Eduardo Sánchez and Daniel Myrick. Perf. Heather Donahue, Joshua Leonard, Michael C. Williams. Haxan Films, 1999. DVD.

Walpole, Horace. The Castle of Otranto: A Gothic Novel. Auckland: The Floating, 2009. Kindle file.

Tomasz SawcZuk is Assistant Professor at the Faculty of Philology, University of Bialystok, Poland. He has authored On the Road to Lost Fathers: Jack Kerouac in a Lacanian Perspective (Peter Lang, 2019), as well as a number of essays on American literature and Beat writers, including a chapter contribution to The Routledge Handbook of International Beat Literature, ed. A. Robert Lee (Routledge, 2018). His research interests include Beat studies, critical theory, experimental literature and concrete poetry.

ORCID: 0000-0003-3357-8303

t.sawczuk@uwb.edu.pl 